\title{
Pattern visual evoked responses in hereditary spastic paraplegia
}

\author{
I R LiVingStone, F L MASTAGLiA, R EDIS, AND J W HOWE \\ From the Muscular Dystrophy Group Research Laboratories, Regional Neurological Centre, \\ Newcastle General Hospital, Newcastle upon Tyne
}

SUMmaRY Pattern visual evoked responses were studied in 13 patients from nine families with dominant hereditary spastic paraplegia and in seven sporadic cases. The responses were normal in all the dominantly inherited cases but abnormal in three of the seven sporadic cases.

Hereditary spastic paraplegia (HSPP) or StrümpellLorraine disease is characterised clinically by progressive lower limb spasticity ${ }^{1}$ and pathologically by degeneration of the corticospinal tracts and (to a lesser degree) of the posterior columns and spinocerebellar tracts. ${ }^{23}$ The condition is usually dominantly inherited but recessive and X-linked forms also occur. ${ }^{4-6}$ Reduced visual acuity and optic atrophy have been reported ${ }^{1-5}$ but there is little data on the frequency of visual involvement in the different genetic forms of HSPP. $^{7-9}$ We studied the visual evoked response (VER) to pattern reversal in a group of patients with HSPP with normal vision to determine how frequently subclinical involvement of the visual pathway occurs.

\section{Patients}

Fourteen patients (eight males and six females, cases 1-14, table) from Newcastle upon Tyne and six from Perth, Western Australia were studied. Their mean age was 43.9 years; mean duration of symptoms 19.8 years. All had slowly progressive lower limb spasticity without relapses or remissions and none had visual symptoms. All had mild pyramidal weakness of the lower limbs with pathologically brisk tendon reflexes and extensor plantar responses; three also had spasticity and hyperreflexia in the upper limbs. Six had bilateral pes cavus. In 12 cases there was reduced appreciation of vibration sense in the lower

Address for reprint requests: Associate Professor FL Mastaglia, The University Department of Medicine, The Queen Elizabeth II Medical Centre, Nedlands, WA 6009, Australia.

Accepted 26 August 1980
Table Summary of clinical and neuro-ophthalmic findings in 20 patients with progressive spastic paraplegia

\begin{tabular}{|c|c|c|c|c|c|c|}
\hline Case & $\begin{array}{l}\text { Sex } \\
\text { and age } \\
\text { (years) }\end{array}$ & $\begin{array}{l}\text { Duration } \\
\text { of symptoms } \\
\text { (years) }\end{array}$ & $\begin{array}{l}\text { Family } \\
\text { history }\end{array}$ & $\begin{array}{c}\text { Visuc } \\
\text { acuit } \\
R\end{array}$ & & $V E R$ \\
\hline 1 & $F, 33$ & 8 & + & $6 / 9$ & $6 / 6$ & $\mathbf{N}$ \\
\hline 2 & $\mathbf{M}, 10$ & 6 & + & $6 / 5$ & $6 / 5$ & $\mathbf{N}$ \\
\hline 3 & M, 53 & 10 & + & $6 / 9$ & $6 / 6$ & $\mathbf{N}$ \\
\hline 4 & M, 56 & 36 & + & $6 / 6$ & $6 / 6$ & $\mathbf{N}$ \\
\hline 5 & M, 54 & 24 & + & $6 / 9$ & $6 / 9$ & $\mathbf{N}$ \\
\hline 6 & M, 46 & 15 & + & $6 / 5$ & $6 / 5$ & $\mathbf{N}$ \\
\hline 7 & $F, 56$ & 30 & + & $6 / 9$ & $6 / 9$ & $\mathbf{N}$ \\
\hline 8 & F, 31 & 23 & + & $6 / 6$ & $6 / 6$ & $\mathbf{N}$ \\
\hline 9 & $M, 14$ & 4 & + & $6 / 5$ & $6 / 5$ & $\mathbf{N}$ \\
\hline 10 & $\mathbf{M}, 30$ & 20 & - & $6 / 5$ & $6 / 5$ & $\mathbf{N}$ \\
\hline 11 & $F, 47$ & 5 & - & $6 / 6$ & $6 / 6$ & $\mathbf{R}$ delayed \\
\hline 12 & M, 52 & 12 & - & $6 / 9$ & $6 / 9$ & $\mathbf{N} \ddagger$ \\
\hline 13 & F, 52 & 14 & - & $6 / 6$ & $6 / 6$ & $\mathbf{N}$ \\
\hline 14 & $F, 61$ & 20 & - & $6 / 9$ & $6 / 9$ & R \& L delayed \\
\hline 15 & $M, 55$ & 35 & + & $6 / 36$ & $6 / 5$ & $\mathbf{R}$ absent $\dagger$ \\
\hline 16 & M, 29 & 8 & + & $6 / 6$ & $6 / 6$ & $\mathbf{N}$ \\
\hline 17 & $F, 56$ & 50 & - & $6 / 9$ & $.6 / 6$ & $\mathbf{N}$ \\
\hline 18 & F, 54 & 33 & + & $6 / 12$ & $6 / 9$ & $\mathbf{N}$ \\
\hline 19 & $\mathrm{M}, 52$ & 22 & + & $6 / 5$ & $6 / 5$ & $\mathbf{N}$ \\
\hline 20 & $F, 37$ & 27 & - & $6 / 5$ & $6 / 5$ & $\mathbf{N}$ \\
\hline
\end{tabular}

* Corrected for refractive errors. †Post-traumatic visual loss. $\ddagger$ Normal P2 latencies but increased inter-ocular P2 latency difference. $\mathrm{N}=$ normal.

limbs without impairment of other sensory modalities. Apart from case 15 who had unilateral posttraumatic visual loss, the visual acuity, colour vision, visual fields and optic discs and retinae were normal in all cases.

The 13 familial cases came from nine families, each with affected members in at least two successive generations indicating autosomal dominant transmission. Cases 1 and 2 were mother and son, and cases $3,4,5$ and 6 were brothers. 


\section{Method}

VERs were recorded from $\mathrm{Ag} / \mathrm{Ag} \mathrm{Cl}_{2}$ disc electrodes during monocular pattern stimulation. The active electrode was at $\mathrm{Oz}$, reference electrode at $\mathrm{Cz}$ or $\mathbf{P z}$ (Perth study) (10-20 system). In the Newcastle study a television pattern generator was used for stimulation. ${ }^{10}$ The frequency of reversal of the frame-locked pattern was $2 \mathrm{~Hz}$ (transient VER) or $12 \mathrm{~Hz}$ (steady state response). The transition time for frame pattern reversal was $20 \mathrm{~ms}$. At the viewing distance of 1.7 metres the screen subtended angles of $17^{\circ} 12^{\prime}$ and $13^{\circ}$ at the eye; each check had a visual subtense of $50^{\prime}$. Maximal contrast was used, luminance was kept constant; 128 responses were averaged using a Medelec DAV 6 digital averager triggered by each pattern reversal. In the Perth cases pattern stimulation was carried out using the rotating mirror system; full details of the technique are given elsewhere. ${ }^{11}$ Subjects fixated on a central spot on the screen and those with refractive errors wore corrective lenses. The latencies of the major positive component ( $\mathrm{P} 2$ or $\mathrm{P} \overline{100}$ ) and of the first and second negative peaks (N1 and N2) were determined. The N2-N1 latency difference was used as an index of temporal dispersion, and the amplitude was defined as the N1-N2 potential difference. The interocular P2 latency difference was also calculated. Normal ranges for these parameters were established in 32 healthy volunteers (aged 12-57 years) in the Newcastle study and 50 normal subjects (aged 1765 years) in the Perth study by taking the means \pm 2.5 standard deviations. The upper limit for P2 latency was $131 \mathrm{~ms}$ in the Newcastle study and $113 \mathrm{~ms}$ in the Perth study, ${ }^{11}$ and for the P2 interocular latency difference $6 \mathrm{~ms}$ in both series.

\section{Results}

All VER parameters were normal in 17 of the 20 cases, including all of the six Perth cases. In

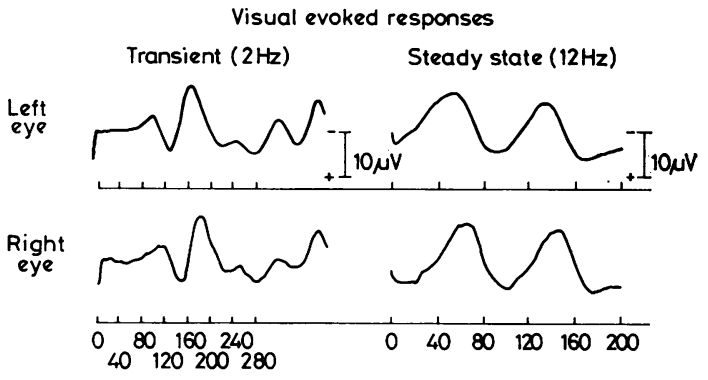

Figure VER tracing from case 11 showing a delayed response on the right with prolonged P2 latency of the transient response and delay in the waveform of the steady state response. the remaining three cases $(11,12,14)$ there were unilateral or bilateral latency changes. In case 11 the P2 latency for the left eye was normal (128 ms) while that for the right eye was prolonged (146 ms) (figure). In case 12 the P2 latencies for the two eyes fell within the normal range (R $120 \mathrm{~ms}$; L $108 \mathrm{~ms}$ ) but the interocular latency difference was increased $(12 \mathrm{~ms})$. Case 14 had bilaterally delayed responses, the right $(156 \mathrm{~ms})$ and the left $(148 \mathrm{~ms})$. The three patients with abnormal VERs were all sporadic cases. Each had previously had a normal myelographic study. and a CSF $\gamma$-globulin estimation performed in two cases was normal; the third case had a normal CSF protein level but a $\gamma$-globulin estimation was not done.

\section{Discussion}

The present findings of normal VERs in cases of dominant HSPP and abnormal responses in three of seven sporadic (presumably recessively inherited) cases contrast with those of Happell et al. ${ }^{7}$ In that study flash VERs were performed in six patients with recessive HSPP and five with dominant HSPP. Responses were abnormal in nine cases, with greatly increased latencies, and borderline in the other two. Athough flash VERs were not recorded in the present study, it is unlikely that abnormalities would have been detected with the flash VER in cases with normal responses to pattern reversal. The most likely explanation for the discrepant findings in the two studies is that involvement of the visual pathway occurs in some families with dominant or recessive HSPP but not in others.

The finding of abnormal VERs in some sporadic cases of HSPP is open to two interpretations. Firstly, the visual pathway may be involved in these cases as part of a multisystem degeneration. Alternatively, they may have a chronic progressive form of spinal multiple sclerosis with asymptomatic involvement of the visual pathway rather than HSPP. The VER abnormality found in these cases, namely a unilateral or bilateral delay, is indistinguishable from that found in patients with demyelinating optic neuropathy. ${ }^{12}$ Although there were no other features of MS in these cases, this possibility cannot be excluded as a proportion of such cases are found to have demyelinating disease at post-mortem. ${ }^{13}$

Further studies are required to determine the frequency of visual involvement and the extent of phenotypic variation in the different genetic forms of HSPP. 
We thank Dr JL Black in whose laboratory the Perth cases were studied and Mr Keith Mitchell for technical assistance.

\section{References}

1 Bickerstaff ER. Hereditary spastic paraplegia. J Neurol Neurosurg Psychiatry 1950; 13:134-45.

2 Behan WMH, Maia M. Strümpell's familial spastic paraplegia: genetics and neuropathology. J Neurol Neurosurg Psychiatry 1974; 37:8-20.

3 Sutherland JM. Familial spastic paraplegia. In: Vinken PJ, Bruyn GW, eds. Handbook of Clinical Neurology, vol 22. Amsterdam: North-Holland Publishing Company, 1975: 421-31.

4 Bell J, Carmichael EA. On hereditary ataxia and spastic paraplegia. In: Fisher RA, ed. Treasury of Human Inheritance. Cambridge University Press, 1939; 4:141-281.

5 Haldane JBS. The partial sex linkage of recessive spastic paraplegia. J Genet 1941; 41:141-7.

6 Johnston AW, McKusick VA. A sex-linked recessive form of spastic paraplegia. Am J Hum Genet 1961; 13:83-93.
7 Happel LT, Rothschild H, Garcia C. Visual evoked potentials in two forms of hereditary spastic paraplegia. Electroencephalogr Clin Neurophysiol 1980; 48:233-6.

8 Asselman P, Chadwick DW, Marsden CD. Visual evoked responses in the diagnosis and management of patients suspected of multiple sclerosis. Brain 1975: 98:261-82.

9 Halliday AM, McDonald WI, Mushin J. Delayed visual evoked response in progressive spastic paraplegia. Electroencephalogr Clin Neurophysiol 1974; 37:328.

10 Arden GB, Faulkner DJ, Mair C. A versatile television pattern generator for visual evoked potentials. In: Desmedt JE, ed. Visual Evoked Potentials in Man: New Developments. Oxford: Clarendon Press, 1977: 90-109.

11 Collins DWK, Black JL, Mastaglia FL. Pattern reversal visual evoked potential. J Neurol Sci 1978; 36:83-95.

12 Halliday AM, McDonald WI, Mushin J. The visual evoked response in the diagnosis of multiple sclerosis. Br Med J 1973; 4:661-4.

13 Marshall J. Progressive spastic paraplegia in middle age. Lancet 1955 ; i:643-6. 